\title{
Function and Implementation of Emotional Teaching in Vocational Physical Education
}

\author{
Qian Sha \\ Tianjin Electronic Information College, China \\ Email: shaqian2356@126.com
}

Keywords: Vocational; Physical education; Emotional teaching; Function

\begin{abstract}
Emotional teaching is an important part in physical education, which is required for training comprehensive talents in vocational colleges. Students' self-confidence and self-esteem can be enhanced by implementing emotional teaching in vocational physical education, which is beneficial for cultivating students' sense of responsibility and brave fighting spirit. In the paper, function and implementation of emotional teaching in vocational physical education are analyzed and studied. Emotional teaching contents in vocational physical education and main function of emotional teaching in vocational physical education are analyzed, thereby proposing method and approaches of implementing emotional teaching in vocational physical education.
\end{abstract}

\section{Introduction}

Physical education is greatly different from teaching of other courses in vocational college, which has own unique characteristics. Physical education is a complex activity integrating physical activity, emotional experience and mental activity, which belongs to dynamic teaching activity and pays great emphasis on participation of teachers and students. Emotional teaching plays the roles of regulation, information transfer, development, innovation, etc. in physical education.

\section{Emotional Teaching in Vocational Physical Education}

Meaning of Emotional Teaching. Emotional teaching is also called teaching in emotional area. Teaching is organized according to unified teaching rules, the main means includes organization of corresponding teaching activities for stimulating change in students' emotional state, and triggering new emotion, cognition and experience, and then new emotions and characteristics are formed[1]. Students not only should master basic knowledge of sports, but also should master method of scientifically exercising body by physical education teaching, and students can form habit of exercising body and realize the purpose of life-long physical education[2-3]. They can enjoy teacher friendship and love in physical education curriculum healthily and happily, thereby realizing the purpose of mental and physical health. The emotional teaching has extraordinary and profound purposes, students' sentiments can be cultivated by emotion. Emotional exchange and communication between students and teachers are prominently important for vocational colleges in the teaching process, which acts as link and bridge of student main bodies. Teachers devote positive emotions in teaching, which is objective requirement of humanistic care in modern subject education, one of necessary teaching means in contemporary teaching, and a great breakthrough in conventional teaching method. It has far-reaching significance to realize long-term educational goals[4].

Emotional Teaching Content in Vocational Physical Education. (A)Education of Love and Hate Emotion. Vocational physical education teaching is combined with teaching contents. Teachers should catch the chance to describe deeds of elite athletes to fight bravely and achieve glory for motherland, and inspire students' patriotism; Assistance and protection in teaching are utilized for fully reflecting teacher-student love and classmate love, and forming excellent atmosphere and friendly collective with mutual concern, mutual assistance, mutual learning, mutual studying and common improvement[5]. Emotion has the role of enhancing force according to bipolar feature of 
emotion, thereby they can feel beautiful life, and achieve loving attitude on surrounding environment, and they can love life, collective, nature, life and learning.

(B)Aesthetic Education. Artistic sense makes people happy. People can feel life fun and life significance through artistic influence. Aesthetic education in vocational physical education teaching includes the follows: environmental beauty, such as tidy and clean site without debris, site layout, equipment placement, neat, beautiful, harmonious and reasonable queuing; beautiful appearance, consistent dress, neat team, glowing spirit, sufficient vigor and vitality, physical beauty, such as even shape, moderate proportion, beautiful line, upright posture, sufficient, strong and robust muscles; artistic beauty, physical education sport itself is a sport art, teachers can easily and skillfully show artistic action gestures in front of students through own demonstration actions, thereby students can achieve pursuit and longing on beauty.

(C)Education of Honor Sense. Physical education teaching is conducted in the form of class collective or team. Activity contents are mostly completed by mutual cooperation between teachers and students and among students. The exercise process gives students time and space for fully manifesting own ability[6]. Mental distance among them can be shortened for emotion harmony. Vocational colleges can fully embody collective unity spirit and team cooperation spirit in teaching competition, and students can experience realization of own value, thereby obtaining strong self-esteem, self-confidence and honor sense.

(D)Education of Happiness and Well-being. The pace of life in modern society is accelerated, social competition is intense, students in vocational college face relatively large employment pressure, and they often suffer from tension, anxiety and other negative mental states. Mental bearing capacity of people can be enhanced by strengthening happiness and well-being education, thereby treating all aspects in life with optimism emotion on one hand, and students also can adjust thinking mechanism and promote intellectual development[7]. Various sports games in physical education teaching, happy physical education and pleasure after physical exercise can enable students to create sense of joy, happiness and satisfaction.

\section{Main Function of Emotional Teaching in Vocational Physical Education}

Regulation Function. Physical Education Teaching process is an activity process with strong purpose, which requires joint effort of students and teachers. Enthusiasm of both parties in teaching can be mobilized by positive emotion, thereby motivating students and teachers to overcome various internal and external resistance and difficulties, thereby ensuring realization of physical education teaching goals. Negative emotion has the function of reducing force, which has negative influence on physical education teaching purpose and hinders realization of physical education teaching goals. Suhomlinski said that: "If the teachers do not try to enable students to produce high emotion and intellectual uplifting mental state, and are eager to impart knowledge, the knowledge only can make people to produce apathy, and fatigue can be produced due to brain labor without emotion'. Surely, degree of emotion also should be controlled at an appropriate level.

Function of Information Transfer. Emotion of teachers and students, as teaching subjects, has specific facial expressions, movements, demeanor and tone in physical education teaching process. Signal system for expressing mental world is formed with function of information transfer. It plays an important role in physical education teaching activity, and even language signals are also far inferior sometimes, namely 'silence speak'. Specific performances are shown as follows: Firstly, teacher can subtly transfer his love, trust, hope, praise, encouragement, motivation, criticism and other information on students through expression so that students can take the hint, thereby enabling students to mobilize their own enthusiasm. They can actively participate in the process, make progress strenuously, and make efforts to complete teaching task. Secondly, teachers can carefully and accurately grasp the students' inner world through expression, and timely discover the problems of students, thereby better organizing teaching. The whole process of physical education is vivid, orderly, systematic and efficient. 
Development Function. Cognition requires emotional wake and activation. Emotion determines cognition mode and rate. Students with negative emotion and high intelligence are not always smooth in recognizing and solving problems, and they always in vain. The students with general intelligence can have a brainwave in danger. Student mental stage can be maximally developed by integrating high IQ and high EQ, coordinating and unifying emotion and cognition. In addition, emotion, will, character, hobby and temperament constitute stable and unique psychological factors of personality, and emotional status which is particularly important. Emotion and other psychological factors can penetrate and actively exert own functions in physical education teaching, students' cognitive process can be proactive and effective, the student's personality can be perfected, thereby becoming an independent, wise, tenacious, dynamic and emotional person with all-round development.

Innovation Function. Physical education teaching should not be a repetitive activity, but an activity with continuous innovation. It requires devotion of cognition, emotion and other psychological factors from teaching subjects. Positive emotion allow teachers and students to be in the active state. Students can enjoy mind emancipation, idea updating, spiritual freedom and active thinking, and they can boldly break convention so that the creative potential of students can break out. Both parties can teach and study with their own unique perspective, thereby further enhancing students' innovation awareness and innovation ability.

\section{Method and Approach of Implementing Emotional Teaching in Vocational Physical Education}

Positive emotion have exchange, incentive and benefit functions on all students in physical education process of vocational colleges, which is beneficial for improving own level of teachers on one hand, and helpful for growth of participants. Therefore, classroom emotional setup and emotional education contents in many aspects should be fully utilized in physical education teaching process.

Creation of Excellent Cultural Environment in Physical Education. Human emotion is generated in certain circumstance, which can be changed with environmental change. Emotional education touching participant soul should exert role in a good atmosphere. Teachers should strive to master rule of emotional education, and create lively physical education atmosphere. Students can learn knowledge and master skills in happiness. Students should be stimulated to devote active emotion in physical education activity as far as possible in daily teaching process. Good physical education quality and physical education accomplishment of a person is trained and cultivated in physical education classroom teaching. Therefore, teachers should apply novel and flexible teaching methods with rich contents to create harmonious atmosphere in daily classroom teaching process, therefore students can strive to study with full enthusiasm.

Being Good at Utilizing Performance Desire in Physical Education. Students are in continuous mature growth stage with rapid physical and mental development. Full energy, curiosity and aggressive nature allow students to produce strong desire of performance. Teachers should use incentives to give more positive evaluation so that students should dare to behave and enjoy performance on goal or direction desired by teachers. Active evaluation given by teacher can make students to produce sense of security, sense of success and sense of pride. Inner positive emotion of students also can drive students to actively and consciously play the role of learning owner. Hard studying is regarded as own obligations and responsibilities.

Cultivating Students' Emotion of Enjoying Physical Education in Physical Education. Knowledge imparting, sports technology and emotion cultivation are three aspects which are tightly linked in teaching process. Students should experience emotional education in teaching and training process during vocational physical education teaching; education content scientific and ideological features should be unified. Therefore, teachers must provide realistic and feasible emotional education goals, and try to search combination points of knowledge and emotion in the teaching process. They should teach clearly and thoroughly, and students should comprehend completely. Student motivation should be moderately stimulated so that students can reach suitable tense state in exercise, and students can produce distinctive and intense emotional experience. Therefore, teachers should stimulate students' 
positive and profound emotional experience with novel and varied teaching method and means based on the situation, thereby improving students' attention to practice, obtaining the best practice effect, and mastering chances and intensity of emotion training. Students' serious and fact-respecting attitudes of students, and their determination to promote own growth and hard training for winning reputation are cultivated through teachers' demonstration and students' exercise.

Rational Use of Setback Education in Physical Education Teaching. Physical education class should strengthen personality education, entertainment education and setback education on students according to change analysis of social demand on mental health education. Currently, suicide crisis of domestic college students is increased without decrease according to statistics. It is obvious that it is urgent to strengthen psychological setback education. PE class has its unique educational resources because of high frequency of adverse psychological stimuli in sports. For example, students' stimulation of mistake, falls, embarrassing and other gaffes in front of public appear frequently, correct guidance of teacher is also available, which is very beneficial to improve students' ability to resist setback. It is important to guide students to experience themselves in setback, recognize failure cause, and discover the factors leading to own failure. They can learn to face failure in life, and this is also a part that should be learned by people. Triumph and failure, success and setbacks happen frequently in physical education activity. Teachers should give encouragement and assistance, and analyze failure cause when students suffer from setback and failure. Students' self-confidence can be gradually improved in the process through utilizing the mode of lowering action difficulty, overcoming psychological barriers - completing technology behaviors.

\section{Summary}

Physical education in vocational colleges implements emotional teaching, which can make students to release emotion of obtaining success in physical education practice. Positive emotion can be transformed into power for students to study, thereby improving internal force for students to participate in physical education exercise, enhancing students' learning enthusiasm in learning, being beneficial for enhancing students' sports ability, and achieving positive significance for students' healthy mental state. Emotional teaching exerts more and more important role in modern physical education process. Emotional teaching theory is applied in practice. Good cultural environment is created in physical education. A variety of teaching methods are utilized for emotional education. Performance desire of participants should be utilized well, thereby ensuring harmonious teacher-student relationship, which is conducive to utilizing emotional teaching of vocational physical education, enhancing exchange between teachers and students, improving power of students to learn and exercise, enhancing efficiency of physical education, promoting overall quality of students, and realizing long-term education objectives of physical education.

\section{References}

[1] LU Jiamei. The Research on the Psychology of Affective Instruction, J. Journal of Psychological Science. 2012,35(3):522-529.

[2] WANG Fengqi. Pilot Study of Emotion Teaching Applied to P. E, J. Journal of Inner Mongolia University for Nationalities(Natural Sciences). 2007,22(6):716-718.

[3] CHENG Gang. The Application of The Emotion Teaching in Physical Education Teaching, J. Journal of Pingyuan University.2003,20(4):66-67.

[4] LIU Ying. Research on Physical Education emotion teaching, J. Journal of Shanghai Ocean University.2012,21(1):156-160.

[5] HUANG Linsen. Analysis of Emotion Teaching of P. E , J. Journal of Hubei Sports Science.2008,27(5):511-512. 
[6] GONG Jian. On the Emotional in University P. E Class Higher , J. Journal of Anhui Institute of Education.2005,23(3):108-110.

[7] Wang Jingru.Analysis of affective education in physical education teaching colleges and universities , J. Journal of Jiamusi Education Institute.2013,2:153-154. 